\title{
Quantification of toxins in a Cry1Ac + CpTI cotton cultivar and its potential effects on the honey bee Apis mellifera $\mathbf{L}$.
}

\author{
Peng Han · Chang-Ying Niu $\cdot$ Chao-Liang Lei $\cdot$ \\ Jin-Jie Cui $\cdot$ Nicolas Desneux
}

Accepted: 22 July 2010/Published online: 11 August 2010

(C) The Author(s) 2010. This article is published with open access at Springerlink.com

\begin{abstract}
Transgenic Cry1Ac + CpTI cotton (CCRI41) is increasingly planted throughout China. However, negative effects of this cultivar on the honey bee Apis mellifera L., the most important pollinator for cultivated ecosystem, remained poorly investigated. The objective of our study was to evaluate the potential side effects of transgenic Cry1Ac + CpTI pollen from cotton on young adult honey bees A. mellifera L. Two points emphasized the significance of our study: (1) A higher expression level of insecticidal protein Cry1Ac in pollen tissues was detected (when compared with previous reports). In particular, Cry1Ac protein was detected at $300 \pm 4.52 \mathrm{ng} \mathrm{g}^{-1}$ [part per billion (ppb)] in pollen collected in July, (2) Effects on chronic mortality and feeding behaviour in honey bees were evaluated using a no-choice dietary feeding protocol with treated pollen, which guarantee the highest exposure level to bees potentially occurring in natural conditions (worst case scenario). Tests were also conducted using imidacloprid-treated pollen at a concentration of $48 \mathrm{ppb}$ as
\end{abstract}

P. Han · C.-Y. Niu · C.-L. Lei

Hubei Insect Resources Utilization and Sustainable Pest

Management Key Laboratory, Huazhong Agricultural

University, Shizi Moutain Road, Wuhan 430070, China

J.-J. Cui

Institute of Cotton Research, Chinese Academy of Agricultural

Sciences, Huanghe Road, Anyang, China

N. Desneux

Unité de Recherches Intégrées en Horticulture, French National Institute for Agricultural Research (INRA), 400 Route des

Chappes, 06903 Sophia-Antipolis, France

C.-Y. Niu $(\bowtie)$

College of Plant Science \& Technology, Huazhong Agricultural

University, Wuhan 430070, China

e-mail: niuchy2004@yahoo.com.cn positive control for sublethal effect on feeding behaviour. Our results suggested that Cry1Ac + CpTI pollen carried no lethal risk for honey bees. However, during a 7-day oral exposure to the various treatments (transgenic, imidacloprid-treated and control), honey bee feeding behaviour was disturbed and bees consumed significantly less CCRI41 cotton pollen than in the control group in which bees were exposed to conventional cotton pollen. It may indicate an antifeedant effect of CCRI41 pollen on honey bees and thus bees may be at risk because of large areas are planted with transgenic Bt cotton in China. This is the first report suggesting a potential sublethal effect of CCRI41 cotton pollen on honey bees. The implications of the results are discussed in terms of risk assessment for bees as well as for directions of future work involving risk assessment of CCRI41 cotton.

Keywords Honey bees - Transgenic cotton pollen . ELISA · Feeding behaviour · Risk assessment

\section{Introduction}

Genetically modified (GM) crops play an increasingly important role in agriculture, mainly including herbicide resistance, insect pest resistance and disease resistance. In China, the planting area of insect-resistant transgenic cotton has reached $70 \%$ of the total area in current use (Clive 2007; Stone 2008). The wide use of transgenic cotton effectively reduced the occurrence of Helicoverpa armigera on cotton and other host crops in general in China (Wu et al. 2008). However, transgenic Bt (Bacillus thuringiensis toxin) cotton which expresses a single insecticidal protein may induce pest resistance (Ferre and Van Rie 2002). Thus cotton cultivar CCRI41, which expresses 
Cry1Ac (Bt toxin) and CpTI (Cowpea Trypsin Inhibitor), is now used widely to reduce cotton pest populations and delay development of insect resistance (Cui 2003; Gassmann et al. 2009). Cultivar CCRI41 was assessed for its efficacy against pests and was registered by the Chinese government for being commercially available in 2002 throughout China. The Bt toxin (Cry1Ac) targets lepidopteran pests (Höfte and Whiteley 1989) and the CpTI gene is an insect resistance gene which has proved to be useful since its first expression in tobacco (Boulter et al. 1989). The toxins Cry1Ac and CpTI are thought to have complementary effects for reducing the cotton pests in cotton-planting areas. Despite the fact that planting transgenic cultivars has led to great benefits (Wu et al. 2008), the potential negative impact on biodiversity and non-target organisms (especially beneficial arthropods) still needs to be assessed carefully (Dale et al. 2002).

At least one-third of crops are pollinated by insects and other animals, among which honey bees account for $80 \%$ of the total pollinating insects (Klein et al. 2007). Unfortunately, Colony Collapse Disorder (CCD) in honeycombs from Europe and USA since 2006 has caused several billion dollars of direct economic losses by reduction in crop-yields (Murray et al. 2009). CCD appears to be a multifactorial syndrome and multiple causes have been proposed (pests, pathogens, chemical pesticides, GM crops, etc.) (CoxFoster et al. 2007; Desneux et al. 2007; Oldroyd 2007; Cox-Foster and vanEngelsdorp 2009; vanEngelsdorp et al. 2009; vanEngelsdorp and Meixner 2010). Despite no direct demonstrated involvement of GM crops in CCD yet, potential side effects of GM crops on pollinators should be assessed and considered carefully (Andow and Zwahlen 2006; Romeis et al. 2008). Studies have been conducted to assess the potential impact of transgenic crops on pollinators such as honey bees Apis mellifera L. and bumblebees (Girard et al. 1998; Brodsgaard et al. 2003; Pierre et al. 2003; Hanley et al. 2003; Malone et al. 2004; DechaumeMoncharmont et al. 2005; O'Callaghan et al. 2005; Tian et al. 2006; Duan et al. 2008; Liu et al. 2009). Overall, results showed that $\mathrm{Bt}$ toxins have no lethal effect on A. mellifera. However, only few studies have examined sublethal effects of Bt toxins on honey bee, A. mellifera (Kaiser et al. 2001; Ramirez-Romero et al. 2005; Ludy and Lang 2006; Lang and Vojtech 2006; Prasifka et al. 2007; Ramirez-Romero et al. 2008b). Sublethal effects on pollinators, as demonstrated in some of these studies, highlight the importance of assessing risks of GM crops on pollinators.

In Northern China, the Yellow River cotton zone (YRC) is the most important planted area, covering over 5.2 million hectares in 2009 (http://www.agri.gov.cn), and half of Chinese cotton is produced in this area. The flowering period of cotton usually lasts from June to late August, a time during which A. mellifera, the most important pollinator for cotton in the area, collects cotton pollen. Therefore, honey bees are potentially exposed to transgenic cotton pollen. Honey bee larvae and young adults (less than 12 days old) mainly fed on pollen (Haydak 1970). The potential risks of CCRI41 pollen on survival and feeding behaviour of $A$. mellifera need to be assessed for at least two reasons. First, this assessment will generate baseline data on current exposure to the toxins. Second, the high usage of CCRI41 cotton in the YRC zone may represent a risk to pollinators. The risks may be subtler than appears. The oral toxicity of CCRI41 cotton pollen on honeybee mortality and superoxide dismutase (SOD) activities were minor owing to low (but still variable) doses of Cry1Ac and CpTI in cotton pollen (Liu et al. 2009). However, the conclusions of that study in terms of risk assessment for bees only partially reflects the potential risks because (1) the level of Bt toxin in CCRI41 cotton can be highly variable (Liu et al. 2009), (2) the doses tested were far below the worst case exposure scenario for honey bees, and (3) the duration of exposure was short (only 3 days) which contrasts with a chronic exposure that is likely to occur in honey bee hives. In addition, potential sublethal effects of Cry1Ac + CpTI toxins on feeding behaviour of bees needs attention because a recent study on another $\mathrm{Bt}$ toxin (Cry1Ab) demonstrated that exposure to high concentrations disturbed feeding behaviour (Ramirez-Romero et al. 2008b). These concerns hint the need for further investigations on the impact of CCRI41 cotton on honey bee health.

In this case, the aims of our study were (1) to quantify the expression levels of the toxins Cry1Ac and CpTI in the CCRI41 pollen throughout the entire season, and (2) to provide lethal and sublethal toxicity assessments of transgenic CCRI41 cotton pollen on the honey bee, A. mellifera. For the second goal, two main parameters were measured on young adult honey bees: (i) survival of bees during the oral chronic exposure to CCRI41 cotton pollen, and (ii) sublethal effect of toxins on feeding behaviour when feeding on CCRI41 cotton pollen. We used the pesticide imidacloprid as positive control because previous works reported deleterious effects on feeding behaviour of honey bees (Ramirez-Romero et al. 2005, 2008b).

\section{Materials and methods}

\section{Cotton varieties}

Transgenic Cry1Ac + CpTI cotton cultivar CCRI41 and its near-isogenic cultivar CCRI23 (referred to conventional cotton thereafter) were provided by the Institute of Cotton Research, Chinese Academy of Agricultural Sciences. Both cultivars were planted in early May 2009, and 30 g samples 
of each pollen type ( $n=30$ plants) were collected using a multi-point field sampling method on June 20th, July 20th, and August 20th (cotton early bloom, mid-stage bloom and late bloom respectively). Samples were stored at $-80^{\circ} \mathrm{C}$ until they were used for experiments or analyses. Portions of the samples were used for the quantification of the two toxins (Cry1Ac and CpTI) in cotton pollen at the three dates of collection (see below) and the rest was used to conduct the studies on lethal and sublethal effects of CCRI41 cotton pollen on honey bees.

ELISA quantitative detection for proteins Cry1Ac and CpTI in pollen

We use Envirologix Qualiplate Kits (EnviroLogix Quantiplate Kit, Portland, ME, USA) to estimate Cry1Ac quantities. The quantitative detection limit of the Cry1Ac kit was $0.1 \mathrm{ng} \mathrm{ml}^{-1}$ (data from Shanghai YouLong Biotech Co., Ltd). The validity of the Envirologix Qualiplate Kit for quantifying accurately the Cry1Ac toxin was checked during a pilot experiment involving the test of six known increasing doses of Cry1Ac toxin (P. Han and C. Y. Niu, unpublished data). The ELISA polyclonal kits for detecting CpTI protein were provided by the Center of Crop Chemical Control, China Agricultural University (which validated the method). The quantitative detection limit of the CpTI kit was $20 \mathrm{ng} \mathrm{ml}^{-1}$. The CpTI ELISA testing method was used according to the literature (Rui et al. 2004). A BIO-RAD 550 plate reader (BIO-RAD Model 550 , USA) was used to obtain the ODs of sample pollen.

Before analysis for the two insecticidal proteins, the two samples were homogenized in $2 \mathrm{ml}$ extraction phosphate buffered saline tween-20 (PBST; $8.0 \mathrm{~g} \mathrm{NaCl}, 2.7 \mathrm{~g}$ $\mathrm{Na}_{2} \mathrm{HPO}_{4} \cdot 12 \mathrm{H}_{2} \mathrm{O}, \quad 0.4 \mathrm{~g} \quad \mathrm{NaH}_{2} \mathrm{PO}_{4} \cdot 2 \mathrm{H}_{2} \mathrm{O}$, dissolved in $1000 \mathrm{ml}$ water, $\mathrm{pH}=7.4$ ) using liquid nitrogen for complete extraction. Three replicates were performed for each sample type. The homogenized samples were washed with additional $2 \mathrm{ml}$ PBST and kept in $10 \mathrm{ml}$ centrifuge tubes at $4^{\circ} \mathrm{C}$ overnight for extracting the insecticidal proteins. The tubes were then centrifuged at $6900 \mathrm{rpm}$ for $20 \mathrm{~min}$. The supernatants were used for detection of the target proteins using corresponding ELISA kits described above.

\section{Preparation of treated pollen}

Conventional cotton pollen, CCRI41 cotton pollen and imidacloprid-treated conventional cotton pollen were used in the experiments as three different treatments. In case of CCRI41 pollen, samples collected in July were used as they proved to contain the highest amount of Cry1Ac toxin during ELISA tests (see "Results" section). Three different diets were prepared by mixing water, honey and pollen at a rate of 1:2:7 (weight) and the positive sublethal control (imidacloprid-treated pollen) contained imidacloprid at a concentration of $48 \mathrm{ng} \mathrm{g}^{-1}$ (48 ppb) (Ramirez-Romero et al. 2008b).

\section{Chronic exposure and feeding behaviour}

Emerging honey bees were collected from a bee colony during summer and were kept in cages slightly adapted from the Pain cage design (Pain 1966). We used glassmade cages $(15 \times 10.5 \times 20 \mathrm{~cm})$ with the top face covered with a piece of mesh to ensure effective ventilation in the cage. Honey bees had a 2-day adaptive period to rearing conditions in cages and were then used for the experiments. We used a no-choice dietary feeding method in which a single food source was provided to bees. Bees received a mixture of water + honey + pollen (using a chopped $10 \mathrm{ml}$ Eppendorf tube inserted into the cage) with no additional sugar provided. The cages were kept in the dark in an incubator at temperature $33 \pm 1^{\circ} \mathrm{C}$ and $55 \pm 5 \%$ relative humidity. A pile of filter papers was placed at the bottom of the cage to ensure a clean and dry environment for bees during the assays (the pile was changed every day). Four replicates were undertaken per treatment with 40 bees per replicate. The bees were exposed to the different treatments for a 7-day period during which water was offered ad libitum.

The honey bee mortality and pollen consumption rate were recorded daily at 5:00 pm (the tube providing the artificial diet in each cage was weighed on a daily basis). Honey bees were considered dead when they remained completely immobile and these bees were removed from the cages every day (Ramirez-Romero et al. 2008b). The treated pollens and water were replenished subsequently daily.

\section{Statistical analysis}

The proportion of dead honey bees at the end of the oral chronic exposure period among CCRI41 pollen, imidacloprid-contaminated pollen (48 ppb) and conventional pollen were fitted to a log-linear model (using "food type" and "replicate" [four cages per food type] as factors). We tested the effect of food type (CCRI41 pollen, imidacloprid-contaminated pollen, and conventional cotton pollen) and time (day) of experiment on the daily quantity of pollen consumed by the bees. For this, we used a generalized linear model for repeated measure design (Proc Genmod with the GEE option to analyse repeated measures, SAS Institute 1999) (followed by a Tukey's post hoc test for multiple comparisons). Such generalized linear models allow for deficiencies in statistical independence among measures made on the same cage at different days. Finally, cumulative consumption (total consumption during 
the 7 days of chronic exposure) of the various food types by bees was compared using an ANOVA (followed by Tukey's post-hoc test). Datasets were first tested for homogeneity of variance and normality using Cochran's test and Kolmogorov-Smirnov D test respectively, and transformed if necessary.

\section{Results}

ELISA results for Cry1Ac and CpTI in pollen

Protein Cry1Ac and CpTI were detected in CCRI41 pollen during the flowering period from June to August while no Cry1Ac and CpTI were detected in conventional cotton. For CCRI41 pollen, mean contents of Cry1Ac protein in pollen tissue were $158.0 \pm 7.35, \quad 300.0 \pm 4.52$ and $32.8 \pm 3.39 \mathrm{ng} \mathrm{g}^{-1}$ for June 20th, July 20th and August 20th respectively. There was a high variability in levels of Cry1Ac detected among samples from different dates with the highest values in samples collected in July, but a low variability among the samples collected at the same dates. CpTI protein was detectable in CCRI41 cotton pollen but the levels were always lower than the lowest limit of quantification (ILQ) of ELISA polyclonal kits used for detecting CpTI protein.

Mortality of honey bees during chronic exposure

The proportion of dead bees after the 7-day exposure period varied from 13.8 to $21.3 \%$ but did not differ significantly among CCRI41 pollen, imidacloprid-treated pollen and conventional pollen ("food type" factor: $\chi^{2}=5.52, \mathrm{df}=2, P=0.0632$ ) (Table 1). The "replicate" factor and its interaction with "food type" factor were not significant, thus hinting that mortality results were consistent among the various replicates for a given food type (Table 1).

\section{Impact on feeding behaviour}

Daily consumption of pollen differed significantly among food types (i.e. significant food type factor: $\chi^{2}=7.04$, $\mathrm{df}=2, P=0.0296)$ with honey bees consuming significantly more conventional pollen (control) than CCRI41 pollen $(P<0.001)$ and imidacloprid-contaminated pollen $(P<0.001)$. Bees also tended to consume less CCRI41 pollen than imidacloprid-contaminated pollen though it was only marginally significant $(P=0.056)$. Honey bees tended to consume less and less food over the course of the experiment, but it was only marginally significant (day factor: $\chi^{2}=11.77, \mathrm{df}=6, P=0.0672$ ). The interaction between food type and day factors was not significant,
Table 1 Mean percentage of mortality in honey bees after a 7-day period of chronic exposure to conventional pollen, CCRI41 $($ Cry1Ac $+\mathrm{CpTI})$ pollen, and conventional pollen containing imidacloprid at $48 \mathrm{ppb}$ (part per billion) ( $\mathrm{n}=40$ bees per cage)

\begin{tabular}{|c|c|c|c|}
\hline \multicolumn{3}{|l|}{ Treatment } & $\begin{array}{l}\text { Percentage } \\
\text { of mortality }\end{array}$ \\
\hline \multicolumn{3}{|l|}{ Control } & $13.8 \pm 2.4$ \\
\hline \multicolumn{3}{|c|}{ CCRI41 (Cry1Ac + CpTI) } & $21.3 \pm 1.6$ \\
\hline \multicolumn{3}{|l|}{ Imidacloprid } & $20.0 \pm 1.0$ \\
\hline Source of variation & $\begin{array}{l}\text { Degrees } \\
\text { of freedom }\end{array}$ & $\chi^{2}$ & $P$-value \\
\hline Food type & 2 & 5.52 & 0.0632 \\
\hline Replicate & 3 & 0.20 & 0.9782 \\
\hline Food type $\times$ replicate & 6 & 4.80 & 0.5692 \\
\hline
\end{tabular}

Statistics from the log linear model used to analyze the proportion of dead honey bees at the end of the oral chronic exposure period among treatments (food type factor) and as function of replicate factor (four replicates (cages) per food type with 40 individual bees per replicate)

meaning that differential consumption of the three food types was not function of time $\left(\chi^{2}=12.00\right.$, $\mathrm{df}=12$, $P=0.4457)$ (Fig. 1).

Cumulative consumption of pollen (total consumption during the 7 days of chronic exposure) varied significantly in function of the food provided to bees $\left(\mathrm{F}_{2,10}=20.018\right.$; $P<0.001)$. Honey bees fed with CCRI41 pollen and imidacloprid-contaminated pollen consumed significantly less pollen than bees fed with conventional pollen $(P<0.001$ and $P=0.014$, respectively). Consumption of pollen did not differ significantly between bees fed with CCRI41 pollen and bees fed with imidaclopridcontaminated pollen $(P=0.144)$ (Fig. 2).

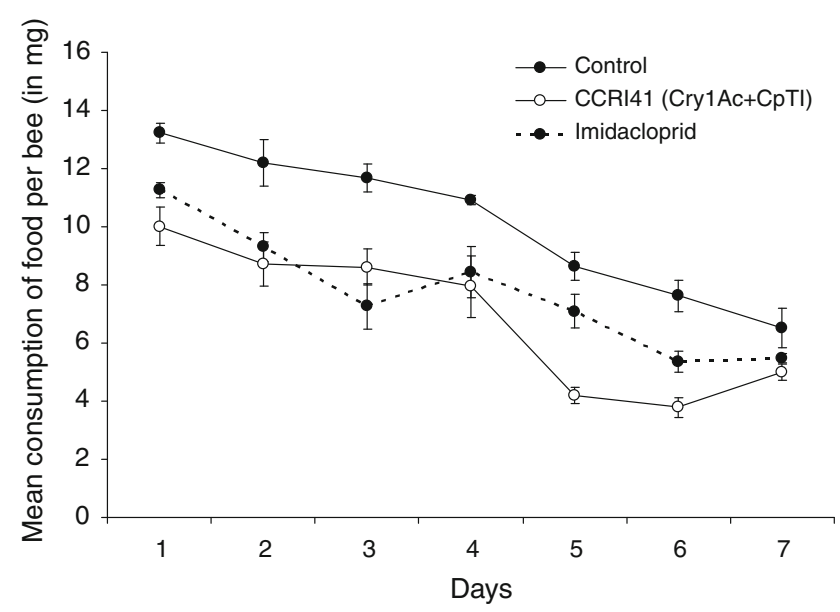

Fig. 1 Mean daily quantity of food consumed ( \pm SEM) by honey bees in groups subjected to chronic exposure to CCRI41 (Cry1Ac + CpTI) pollen, conventional pollen, and conventional pollen containing imidacloprid at $48 \mathrm{ppb}$ (part per billion) during a 7-day oral chronic exposure 


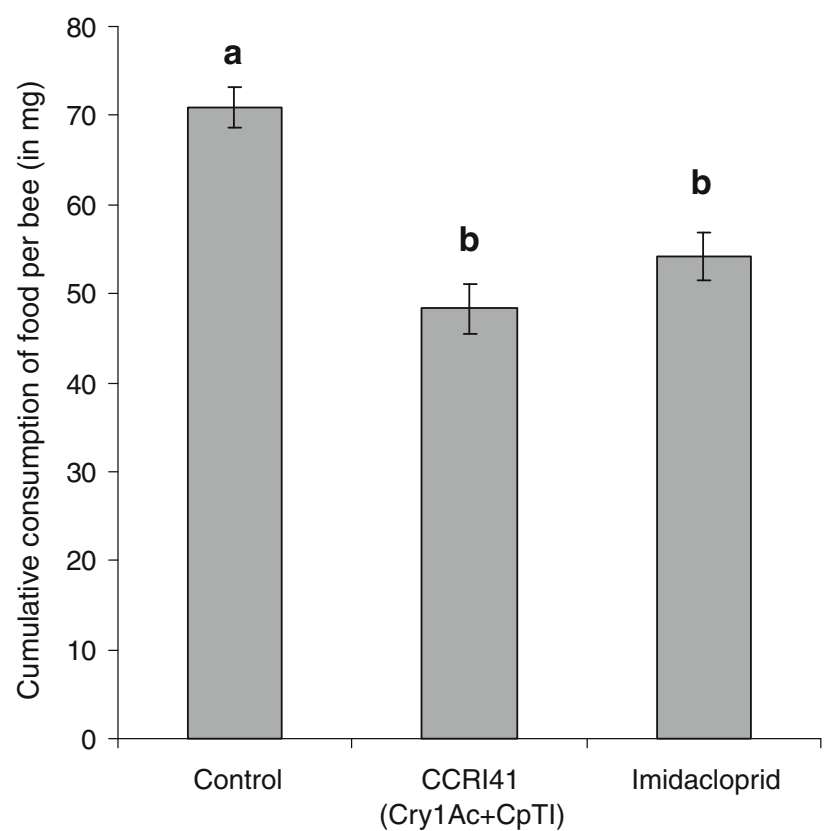

Fig. 2 Mean total quantity of food consumed ( \pm SEM) by honey bees from groups subjected to chronic exposure to conventional pollen, CCRI41 (Cry1Ac + CpTI) pollen, and conventional pollen containing imidacloprid at $48 \mathrm{ppb}$ (part per billion) during a 7-day oral chronic exposure. Values with the same letter are not significantly different at the $P>0.05$ level (ANOVA followed by Tukey's post-hoc test)

\section{Discussion}

A recent study has concluded that CCRI41 cotton pollen did not significantly influence survival and SOD activity in the honey bee (Liu et al. 2009). In our study, a further investigation of potential effect on feeding behaviour was conducted. Although no lethal effect was observed after oral chronic exposure to Cry1Ac $+\mathrm{CpTI}$ cotton pollen in 7 days, results indicated an antifeedant effect on honey bees. Two important differences between our study and those of Liu et al. (2009) may strengthen our findings and their significance. First, the doses of Cry1Ac used in the Liu et al. (2009) study likely underestimated the real exposure level to Cry1Ac through CCRI41 cotton pollen because of highly variable expression level of Cry1Ac in that pollen throughout the season. To perform a more rigorous test, we conducted our experiments using the worst-case exposure scenario, that is using cotton pollen containing the highest dose of Cry1Ac. Second, we used a no-choice feeding protocol and a chronic exposure method which may better mimic the natural feeding conditions in hives because pollen is the major food for young bees after emergence (Haydak 1970) and they consume large amounts until they become foragers (Hrassnigg and Crailsheim 1998).
Potential sublethal effects on honey bees

Young bees in the hive usually ingest an average of $6.5 \mathrm{mg}$ of pollen per day (Rortais et al. 2005). Bees in the CCRI41 group consumed less pollen than control bees during the course of the assay and a similar pattern occurred for bees exposed to imidacloprid-contaminated pollen. The antifeedant effect in group exposed to imidacloprid-contaminated pollen was consistent with previous studies on honey bees (Kirchner 1999; Ramirez-Romero et al. 2005; Ramirez-Romero et al. 2008b) and on Homoptera (Nauen et al. 1998a, b). The detection and uptake of nectar and pollen involves sophisticated nervous system activity which can be perturbed by the presence of chemical insecticide, whether that behaviour took place in the hive or outside (Desneux et al. 2007). Lower consumption of CCRI41 cotton pollen suggests also a potential antifeedant effect on bees, but potential mechanisms that underlie such effect need to be explored. An effect of Cry1Ac and/or $\mathrm{CpTI}$ at the gut level in honey bees would induce lesions and subsequently halt food uptake or cause death as reported in insects sensitive to Cry1 Ab (Schnepf et al. 1998). Therefore our results are probably not caused by a direct effect at the gut level in honey bees though this hypothesis still needs to be tested. For instance, the observed effect likely did not result from different nutritional qualities between CCRI41 and conventional cotton pollen because they present the same nutrients (Liu et al. 2009).

It is crucial to obtain a reliable expression level of insecticidal toxins in target GMO tissues before conducting any risk assessment on non-target organisms because it highly impacts subsequent effect on tested organisms (Romeis et al. 2008). However, the variation in estimated toxin doses caused by using different ELISA kits may lead to inconsistent bioassay results (Nguyen and Jehle 2007; Ramirez-Romero et al. 2008a) and may also lead to error in selecting the correct worst case scenario for conducting risk assessment assays. In our study, we detected much higher Cry1Ac in pollen sampled in July. The lower amounts of Cry1Ac in the Liu et al. (2009) study may be due to variation between the two ELISA kits and/or the use of a lower extraction method. We used the Envirologix Qualiplate Kit to estimate quantities of Cry1Ac, which enabled a high sensitivity $\left(0.1 \mathrm{ng} \mathrm{ml}^{-1}\right)$. In addition, we used liquid nitrogen when homogenizing the sample pollen, and allowed the samples to homogenize over night to ensure a complete extraction of the target proteins (accordingly to State Standard of testing the protein expression of the insect-resistant gene in the transgenic insect-resistant cotton in China). In line with results from a recent study conducted on another GM cotton cultivar that demonstrated temporal variances in Cry1 Ac and Cry1F 
protein expression in cotton (Siebert et al. 2009), our results demonstrated a high variability in doses of Cry1 Ac during the whole season. This shows the importance of assessing toxin levels throughout the season.

Implications for risk assessment of transgenic cotton on non-target organisms

No lethal effect was observed during a 7-day period of oral chronic exposure to transgenic CCRI41 cotton pollen, which is consistent with previous works conducted on CCRI41 (Liu et al. 2009; Chen et al. 2010) and other transgenic toxins (Arpaia 1996; Benedict et al. 1996; Picard-Nizou et al. 1997; Hanley et al. 2003; Malone et al. 2004; Babendreier et al. 2005; Ramirez-Romero et al. 2008b). However, our work demonstrated an antifeedant effect in honey bees feeding on CCRI41 cotton pollen as well as on imidacloprid-contaminated cotton pollen even though the exposure duration is shorter than those reported previously (Rose et al. 2007; Ramirez-Romero et al. 2008b). It is unclear how Bt toxins function in bee's intestines (and more broadly on general bee physiology), which directly or indirectly induced decreased consumption of transgenic cotton pollen in this study. Since a similar sublethal effect has been reported in honey bees exposed to another Bt toxin (Cry1 Ab) (Ramirez-Romero et al. 2008b), it hints at the importance of assessing potentially disturbing effects of Bt toxins on bee feeding behaviour. This effect may potentially lead to insufficient food sources and malnutrition for the larvae and newlyemerged bees, which eventually could result in a demographic decrease of the colony (Desneux et al. 2007; Decourtye et al. 2010). Multiple and/or combined stress factors could contribute to weakening honey bee populations, for example they can allow opportunistic pathogens to infect and eventually kill colonies (Cox-Foster and vanEngelsdorp 2009). Therefore, sublethal effects as the one observed in our study may potentially be of importance in overall bees health. Insufficient pollen consumption in early life of worker bees could results in poor hypopharyngeal gland development (Haydak 1970; Mohammedi et al. 1996), and thus may affect the ability of nurse bees to provision larvae with food later in their life (Crailsheim et al. 1992; Hrassnigg and Crailsheim 1998; Sagili et al. 2005; Wegener et al. 2009). In the YRC zone, if such effects occur in bees from hives largely collecting CCRI41 cotton pollen, it may be unfavourable to the development of honey bee populations and lead to population decreases in a similar way than for CCD. So far no CCD syndrome has been reported in the YRC area but we suggest that more attention should be paid to the potential risk of transgenic cotton crops on the health of honey bees in this area.
When assessing sublethal effects of toxic products on non-target organisms, particular attention should be paid to whether the observed behavioural or physiological perturbations are realistically significant or not, and it highly depends on the real exposure level of organisms to the toxic products tested (Desneux et al. 2007; Romeis et al. 2008). We could estimate the exposure level of honey bees to pollen under natural conditions. Each bee consumed about $78 \mathrm{mg}$ pollen in 12 days to become foragers (Rortais et al. 2005; Ramirez-Romero et al. 2008b). The pollen carried back to the honeycomb is actually a mixture composed of various pollen from different flowering plant species, in which the CCRI41 pollen (Cry1Ac + CpTI) account for approximately $50 \%$ of the total amount because the planting areas of this cultivar in some areas (especially in YRC zone) covered over 50\% of the total cotton areas. Thus, we can estimate that a young bee consumes about $39 \mathrm{mg}(50 \%$ of $78 \mathrm{mg}$ ) of transgenic cotton pollen in 12 days when the hive is in the YRC area. In our laboratory conditions, a mean daily consumption of $6.8 \mathrm{mg}$ of food (containing CCRI41 pollen) per bee per day was observed which means that each young bee has consumed $33.3 \mathrm{mg}$ of the Cry $1 \mathrm{Ac}+\mathrm{CpTI}$ cotton pollen during the 7-day no-choice exposure because the cotton pollen accounted for $70 \%$ of the total weight of the diet provided $(6.8 \mathrm{mg} \times 7$ days $\times 70 \%)$. Therefore, the exposure level in our experiments may be of the same magnitude as under natural conditions and observed effects on bee feeding behaviour may relate to some extent to what could happen under natural conditions.

Our study provided insight on the potential risk of CCRI41 on honey bees under the broader framework of risk assessment of GMOs on non-target organisms. We conclude that CCRI41 cotton carried no risk on survival of honey bees, A. mellifera. However, the effect on feeding behaviour should not be ignored because it suggests a potential side effect of GMO cotton pollen on honey bees. In addition, the exposure to Bt proteins, $\mathrm{CpTI}$ and more generally proteins from GMOs may potentially affect bees foraging behaviour negatively (Ramirez-Romero et al. 2005,2008 b). Notably it might occur for young bees through disturbance in the development of physiological structures which are crucial for olfactory or learning performance (Masson and Arnold 1984; Masson et al. 1993; Decourtye et al. 2003; Desneux et al. 2007). Therefore, an assessment of side effects of CCRI41 cotton pollen on learning capacity and foraging behaviour of honey bees should be conducted and is the subject of a companion study (P. Han, C. Y. Niu and N. Desneux, unpublished data).

Acknowledgments We thank Professor Bao-Min Wang (China Agricultural University) for providing the polyclonal ELISA Kit and 
methods for detecting the CpTI in transgenic cotton pollens, and David Stanley and Jetske deBoer for valuable comments on the manuscript. This work was supported by the project "Risk assessment of GM crops on Nontarget Organisms" grants from Institute of Cotton Research, Chinese Academy of Agricultural Sciences (CAAS).

Open Access This article is distributed under the terms of the Creative Commons Attribution Noncommercial License which permits any noncommercial use, distribution, and reproduction in any medium, provided the original author(s) and source are credited.

\section{References}

Andow DA, Zwahlen C (2006) Assessing environmental risks of transgenic plants. Ecol Lett 9:196-214

Arpaia S (1996) Ecological impacts of Bt-transgenic plants: assessing possible effects of CryIIIB on honeybee (Apis mellifera L.) colonies. J Genet Breed 50:315-319

Babendreier D, Kalberer NM, Romeis J, Fluri P, Mulligan E, Bigler F (2005) Influence of Bt-transgenic pollen, Bt-toxin and protease inhibitor (SBTI) ingestion on development of the hypopharyngeal glands in honeybees. Apidologie 36:585-594

Benedict JH, Sachs ES, Altman DW, Deaton WR, Kohel RJ, Ring DR, Berberich SA (1996) Field performance of cottons expressing transgenic CryIA insecticidal proteins for resistance to Heliothis virescens and Helicoverpa zea (Lepidoptera: Noctuidae). J Econ Entomol 89:230-238

Boulter D, Gatehouse AMR, Hilder V (1989) Use of cowpea trypsininhibitor (CpTI) to protect plants against insect predation. Biotechnol Adv 7:489-497

Brodsgaard HF, Brodsgaard CJ, Hansen H, Lovei GL (2003) Environmental risk assessment of transgene products using honeybee (Apis mellifera L.) larvae. Apidologie 34:139-145

Chen LZ, Cui JJ, Ma WH, Niu CY, Lei CL (2010) Pollen from Cry1Ac/CpTI-transgenic cotton does not affect the pollinating beetle Haptoncus luteolus. J Pest Sci (in press). doi:10.1007/ s10340-010-0319-0

Clive J (2007) Global status of commercialized biotech/GM crops: 2007. ISAAA brief no. 37. ISAAA, Ithaca

Cox-Foster DL, vanEngelsdorp D (2009) Saving the honeybee. Sci Am 300:40-47

Cox-Foster DL, Conlan S, Holmes EC, Palacios G, Evans JD, Moran NA, Quan PL, Briese T, Hornig M, Geiser DM, Martinson V, vanEngelsdorp D, Kalkstein AL, Drysdale A, Hui J, Zhai JH, Cui LW, Hutchison SK, Simons JF, Egholm M, Pettis JS, Lipkin WI (2007) A metagenomic survey of microbes in honey bee colony collapse disorder. Science 318:283-287

Crailsheim K, Schneider LHW, Hrassnigg N, Bühlmann G, Brosch U, Gmeinbauer R, Schöffmann B (1992) Pollen consumption and utilization in worker honeybees (Apis mellifera carnica): dependence on individual age and function. J Insect Physiol 38:409-419

Cui JJ (2003) Effects and mechanisms of the transgenic Cry1Ac Plus CpTI (cowpea trypsin inhibitor) cotton on insect communities. Dissertation, Chinese Academy of Agricultural Sciences, p 2

Dale PJ, Clarke B, Fontes MG (2002) Potential for the environmental impact of transgenic crops. Nat Biotechnol 20:567-574

Dechaume-Moncharmont FX, Azzouz H, Pons O, Pham-Delègue MH (2005) Soybean proteinase inhibitor and the foraging strategy of free flying honeybees. Apidologie 36:421-430

Decourtye A, Lacassie E, Pham-Delègue MH (2003) Learning performances of honeybees (Apis mellifera L.) are differentially affected by imidacloprid according to the season. Pest Manag Sci 59:269-278
Decourtye A, Mader E, Desneux N (2010) Landscape scale enhancement of floral resources for honey bees in agroecosystems. Apidologie 41:264-277

Desneux N, Decourtye A, Delpuech JM (2007) The sublethal effects of pesticides on beneficial arthropods. Annu Rev Entomol 52:81-106

Duan JJ, Marvier M, Huesing J, Dively G, Huang ZY (2008) A metaanalysis of effects of $\mathrm{Bt}$ crops on honey bees (Hymenoptera: Apidae). PLoS ONE 3:e1415. doi:10.1371/journal.pone.0001415

Ferre J, Van Rie J (2002) Biochemistry and genetics of insect resistance to Bacillus thuringiensis. Annu Rev Entomol 47: 501-533

Gassmann AJ, Carriere Y, Tabashnik BE (2009) Fitness costs of insect resistance to Bacillus thuringiensis. Annu Rev Entomol 54:147-163

Girard C, Picard-Nizou AL, Grallien E, Zaccomer B, Jouanin L, Pham-Delègue MH (1998) Effects of proteinase inhibitor ingestion on survival, learning abilities and digestive proteinases of the honeybee. Transgenic Res 7:239-246

Hanley AV, Huang ZY, Pett WL (2003) Effects of dietary transgenic Bt corn pollen on larvae of Apis mellifera and Galleria mellonella. J Apic Res 42:77-81

Haydak MH (1970) Honey bee nutrition. Annu Rev Entomol 15:143-156

Höfte H, Whiteley HR (1989) Insecticidal crystal proteins of Bacillus thuringiensis. Microbiol Rev 53:242-255

Hrassnigg N, Crailsheim K (1998) The influence of brood on the pollen consumption of worker bees (Apis mellifera L.). J Insect Physiol 44:393-404

Kaiser L, Pham-Delègue MH, Ramirez-Romero R (2001) Bt corn and insect helpers. Biofutur 207:30-33

Kirchner WH (1999) Mad-bee-disease? Sublethal effects of imidacloprid on the behavior of honey-bees. Apidologie 30:422

Klein AM, Vaissière BE, Cane JH, Steffan-Dewenter I, Cunningham SA, Kremen C, Tscharntke T (2007) Importance of pollinators in changing landscapes for world crops. Proc R Soc Lond B 274(1608):303-313

Lang A, Vojtech E (2006) The effects of pollen consumption of transgenic Bt maize on the common swallowtail, Papilio machaon L. (Lepidoptera, Papilionidae). Basic Appl Ecol 7: 296-306

Liu B, Shu C, Xue K, Zhou KX, Li XG, Liu DD, Zheng YP, Xu CR (2009) The oral toxicity of the transgenic Bt+CpTI cotton pollen to honey bees (Apis mellifera). Ecotoxicol Environ Safe 72:1163-1169

Ludy C, Lang A (2006) Bt maize pollen exposure and impact on the garden spider, Araneus diadematus. Entomol Exp Appl 118: $145-156$

Malone LA, Todd JH, Burgess EPJ, Christeller JT (2004) Development of hypopharyngeal glands in adult honey bees fed with a Bt toxin, a biotin- binding protein and a protease inhibitor. Apidologie 35:655-664

Masson C, Arnold G (1984) Ontogeny, maturation and plasticity of the olfactory system in the worker bee. J Insect Physiol 30:7-14

Masson C, Pham-Delègue MH, Fonta C, Gascuel J, Arnold G, Nicolas G, Kerszberg M (1993) Recent advances in the concept of adaptation to natural odor signals in the honeybee, Apis mellifera L. Apidologie 24:169-194

Mohammedi A, Crauser D, Paris A, Le Conte Y (1996) Effect of a brood pheromone on honeybee hypopharyngeal glands. C R Acad Sci III 319:769-772

Murray TE, Kuhlmann M, Potts SG (2009) Conservation ecology of bees: populations, species and communities. Apidologie 40: 211-236

Nauen R, Hungenberg H, Tollo B, Tietjen K, Elbert A (1998a) Antifeedant effect, biological efficacy and high affinity binding 
of imidacloprid to acetylcholine receptors in Myzus persicae and Myzus nicotianae. Pestic Sci 53:133-140

Nauen R, Koob B, Elbert A (1998b) Antifeedant effects of sublethal dosages of imidacloprid on Bemisia tabaci. Entomol Exp Appl $88: 287-293$

Nguyen HT, Jehle JA (2007) Quantitative analysis of the seasonal and tissue-specific expression of Cry1 Ab in transgenic maize Mon810. J Plant Dis Prot 114:82-87

O'Callaghan M, Glare TR, Burgess EPJ, Malone LA (2005) Effects of plants genetically modified for insect resistance on nontarget organisms. Annu Rev Entomol 50:271-292

Oldroyd BP (2007) What's killing American honey bees? PLoS Biol 5:1195-1199

Pain J (1966) Nouveau modèle de cagettes expérimentales pour le maintien d'abeilles en captivité. Ann Abeille 9:71-76

Picard-Nizou AL, Olsen L, Pioche C, Arnold G, Pham-Delègue MH (1997) Impact of proteins used in plant genetic engineering: toxicity and behavioural study in the honeybee. J Econ Entomol 90:1710-1716

Pierre J, Marsault D, Genecque E, Renard M, Champolivier J, PhamDelègue MH (2003) Effects of herbicide-tolerant transgenic oilseed rape genotypes on honey bees and other pollinating insects under field conditions. Entomol Exp Appl 108:159-168

Prasifka PL, Hellmich RL, Prasifka JR, Lewis LC (2007) Effects of Cry1 Ab-expressing corn anthers on the movement of monarch butterfly larvae. Environ Entomol 36:228-233

Ramirez-Romero R, Josette C, Pham-Delègue MH (2005) Effects of $\mathrm{Cry} 1 \mathrm{Ab}$ protoxin, deltamethrin and imidacloprid on the foraging activity and the learning performances of the honeybee Apis mellifera, a comparative approach. Apidologie 36:601-611

Ramirez-Romero R, Desneux N, Chaufaux J, Kaiser L (2008a) Bt-maize effects on biological parameters of the non-target aphid Sitobion avenae (Homoptera: Aphididae) and Cry1 Ab toxin detection. Pestic Biochem Physiol 91:110-115

Ramirez-Romero R, Desneux N, Decourtye A, Chaffiol A, PhamDelègue MH (2008b) Does Cry1Ab protein affect learning performance of the honey bee Apis mellifera L. (Hymenoptera, Apidae)? Ecotoxicol Environ Safe 70:327-333

Romeis J, Bartsch D, Bigler F et al (2008) Assessment of risk of insect-resistant transgenic crops to non-target arthropods. Nat Biotechnol 26:203-208

Rortais A, Arnold G, Halm MP, Touffet-Briens F (2005) Modes of honeybees exposure to systemic insecticides: estimated amounts of contaminated pollen and nectar consumed by different categories of bees. Apidologie 36:71-83
Rose R, Galen PD, Pettis J (2007) Effects of Bt corn pollen on honey bees: emphasis on protocol development. Apidologie 38: 368-377

Rui YK, Wang BM, Li ZH, Duan LS, Tian XL, Zhai ZX, He ZP (2004) Development of an enzyme immunoassay for the determination of the cowpea trypsin inhibitor (CpTI) in transgenic crop. Sci Agric Sin 37:1575-1579

Sagili RR, Pankiw T, Zhu-Salzman K (2005) Effects of soybean trypsin inhibitor on hypopharyngeal glandprotein content, total midgut protease activity and survival of the honey bee (Apis mellifera L.). J Insect Physiol 51:953-995

SAS Institute (1999) SAS/Stat user's guide, release 8. SAS Institute, Cary

Schnepf E, Crickmore N, Van Rie J, Lereclus D, Baum J, Feitelson J, Zeigler DR, Dean DH (1998) Bacillus thuringiensis and its pesticidal crystal proteins. Microbiol Mol Biol Rev 62:775-806

Siebert MW, Patterson TG, Gilles GJ, Nolting SP, Braxton LB, Leonard BR, Van Duyn JW, Lassiter RB (2009) Quantification of Cry1Ac and Cry1F Bacillus thuringiensis insecticidal proteins in selected transgenic cotton plant tissue types. J Econ Entomol 102:1301-1308

Stone R (2008) China plans $\$ 3.5$ billion GM crops initiative. Science 321:1279

Tian Y, Zhang YJ, Wu KM, Zhao KJ, Peng YF, Guo YY (2006) Effects of transgenic Bt-cry1Ab corn pollen on the growth, development and enzymes activity in Apis mellifera (L.) (Hymenoptera:Apidae). J Agric Biotechnol 14:990-991

vanEngelsdorp D, Meixner MD (2010) A historical review of managed honey bee populations in Europe and the United States and the factors that may affect them. J Invertebr Pathol (in press). doi:10.1016/j.jip.2009.06.011

vanEngelsdorp D, Evans JD, Saegerman C, Mullin C, Haubruge E, Nguyen BK, Frazier M, Frazier J, Cox-Foster D, Chen Y, Underwood R, Tarpy DR, Pettis JS (2009) Colony collapse disorder: a descriptive study. PLoS ONE 4:a6481. doi:10.1371/ journal.pone. 0006481

Wegener J, Huang ZY, Lorenz MW, Bienefeld K (2009) Regulation of hypopharyngeal gland activity and oogenesis in honey bee (Apis mellifera) workers. J Insect Physiol 55:716-725

Wu KM, Lu YH, Feng HQ, Jiang YY, Zhao JZ (2008) Suppression of cotton bollworm in multiple crops in China in areas with $\mathrm{Bt}$ toxin-containing cotton. Science 321(5896):1676-1678 